\title{
1 ILORA: A database of alien vascular flora of India
}

2

3 Vidushi Pant ${ }^{1}$, Chinmay Patwardhan ${ }^{2}$, Kshitij Patil ${ }^{2}$, Amiya Ranjan Bhowmick ${ }^{2}$, Abhishek

$4 \quad$ Mukherjee $^{3 *}$, Achyut Kumar Banerjee ${ }^{4 *}$

5

$6 \quad{ }^{1}$ Sustainable India Finance Facility, Guntur, Andhra Pradesh, Pin - 522034, India

$7 \quad{ }^{2}$ Department of Mathematics, Institute of Chemical Technology, Mumbai, Maharashtra, Pin -

8400019 , India

$9 \quad{ }^{3}$ Agricultural and Ecological Research Unit, Indian Statistical Institute, Giridih, Jharkhand, Pin -

10 815301, India

$11{ }^{4}$ School of Life Sciences, Sun Yat-sen University, 135 Xingangxi Road, City - Guangzhou, Province

12 - Guangdong, Pin - 510275, China

13

$14 *$ Corresponding author(s)

15 E-mail: $\underline{\text { abhi.mukh@yahoo.com; banerjeeachyut31@outlook.com }}$ 


\section{Abstract}

17 1) Biological invasions pose an unprecedented threat to biodiversity and ecosystems at different spatial scales, especially for a biodiversity-rich developing nation like India. While country-level checklists of alien taxa are important, databases having their biological and ecological attributes are of paramount importance for facilitating research activities and developing policy interventions. Such a comprehensive database for alien flora is lacking in India.

2) We have curated data for 14 variables related to ecology, biogeography, introduction pathway, socio-economy and distribution of 1747 alien vascular plant species from 22 national and global sources to produce the Indian Alien Flora Information (ILORA) version 1.0 database. This paper describes the detailed methodology of curating these data along with the rationale behind selecting these variables.

3) The database, the first of its kind for the Indian alien flora, will provide easy access to high quality data and offer a ready reference to comprehend the existing scenario of alien plant species in the country. The database is dynamic and will be updated regularly. It has a provision to incorporate user submitted data, which will allow increasing the resolution of the database as well as the expansion of its capacity.

4) The database is envisaged to become a nationwide collaborative platform for a wide spectrum of stakeholders. It is freely accessible via an online data repository as well as through a dedicated website (https://ilora2020.wixsite.com/ilora2020). 


\section{Introduction}

Biological invasion has been described as a defining feature of the Anthropocene (van Kleunen et al., 2015). The emerging economies, like India, are facing the greatest threat of invasion as a consequence of increasing globalization of trade as well as the changing climate (Lenzen et al., 2012). This necessitates the creation of a country-level repository of alien flora as the first step towards identifying emerging invaders and managing the ones that have already been established (Pagad et al., 2018). While country-level checklists of alien flora exist in India [e.g. (Khuroo et al., 2012)], the biological and ecological attributes of these alien plant species remain scattered across a multitude of databases rendering their access tedious. Some of this information, although retrievable from global databases, often lack resolution at the national or regional levels (but see The Global Naturalized Alien Flora database, hereafter GloNAF; (van Kleunen et al., 2019). Further, data extraction often involves intensive and informed query-directed search processes to garner species specific information. Easy access to such information at a finer scale is of paramount importance for developing country-level policy interventions and facilitating research and development concerning the alien species of a country. Such a comprehensive database is lacking in India (but see (Inderjit et al., 2018).

Here, we introduce the Indian Alien Flora Information (ILORA) Version 1.0 Database, a dynamic and open-source repository of comprehensive information on taxonomy, introduction pathway, use, and biogeography of 1747 alien vascular plant species of India. Our intention was not to create another country-level checklist, rather we envisage that ILORA will assist in novel research on alien plant invasions in India and can be transformed into a nationwide collaborative platform for stakeholders.

\section{Materials and Methods}

The database formation included two major steps - 1) categorization of the alien flora, and 2) data curation for 14 variables of these species. The steps have been explained in brief in the following text 
along with the overview of the data files (Table 1). The detailed methodology (including resources and search criteria) and the future plans have been provided as supporting information.

\subsection{Categorization of the alien flora}

We created a comprehensive list of alien plant species of India from three national checklists, viz. Alien flora of India (1599 species; (Khuroo et al., 2012), Naturalized alien flora of the Indian states (499 species; (Inderjit et al., 2018), and the GRIIS- India Version 1.3 (2082 species; (Sankaran et al., 2020). The species names were standardized using the WorldFlora package (Kindt, 2020) in $\mathrm{R}$ version 4.0.2 (R Core Team, 2020). The duplicates and synonyms, infraspecific taxa and artificially hybridized species were removed.

The selected plants $(\mathrm{n}=2503)$ were subjected to a two-step verification process (Fig.1) to determine their - i) origin status (native or alien to India) and ii) invasion status (degree of naturalization) (Pyšek et al., 2004). Briefly, we first identified the cultivated aliens $(n=756)$ from the national and global databases. These species were retained in the database; however, no variable information was extracted for these species. The origin status of the remaining species $(n=1747)$ was ascertained using global databases. If the origin status of a species was identified as 'native' or 'alien' to India in at least one of these databases and was not contradicted by the others $(n=1576)$, it was accepted. However, in case of any contradiction between databases $(n=162)$, origin status was determined through literature search. The species with ambiguous origin status were categorized as 'cryptogenic' (i.e., uncertain biogeographic status) following Essl et al. (2018). Therefore, the origin status of the alien species was categorized as - alien $(n=1388)$, native $(n=334)$ and cryptogenic $(n=25)$. From the list of alien species ( $n=1388)$, the 'invasive' species were categorized by consulting the GRIIS database $(n=220)$. The species which have been identified as naturalized aliens by Inderjit et al. (2018) and the GloNAF database, were categorized as 'naturalized' $(n=237)$. The remaining alien species were identified as 'casual alien' (n=931) following Khuroo et al. (2012). Finally, a confidence score was attached to each of the species' categories. It is important to note here that given the vast geographic extent of India, it is possible that some of the species identified as 'native' may be native in one part of the country and 
introduced to others. The status of these species may change by availability of regional-scale data and therefore, we included detailed information of them in the database.

\subsection{Data curation}

\subsubsection{Taxonomy and general information}

For each species, we recorded the class, order and family information. The common names of the species were recorded in English and vernacular languages and standardized using the ISO 6393:2007 code. Besides, information on growth habits, lifecycle (perennial, annual, biennial) and group (monocot/dicot) was also collected for each species.

\subsubsection{Pathway and time of introduction}

Information regarding the introduction pathway and time was retrieved from the literature reports as well as from global databases. If the introduction pathway of the species could not be identified for India, possible purposes for which the concerned species had spread outside of its native range were identified by searching authoritative literature records. The introduction pathways were categorized following the classification framework proposed by the Convention on Biological Diversity (Harrower et al., 2018). The residence status of a species in India was determined by considering the earliest year recorded in the curated data.

\subsubsection{Biogeography}

Native and naturalized range information was collated from the global databases at Level 2 (continental and regional scheme) and Level 4 (constituent political units of a country), respectively, as proposed by the International Working Group on Taxonomic Databases for Plant Sciences (TDWG) (Brummitt et al., 2001).

\subsubsection{Uses and market dynamics}

Usage information of each species was extracted from ethnobotanical literature and databases available in India. The data were supplemented with the usage information reported across the distribution range of a species and standardized according to the thirteen level 1 states of plant uses 
112 (Cook, 1995). Data on species trading, including type, quantity and price, for ornamental purposes 113 were collected from e-commerce platforms.

\subsubsection{Indian distribution}

115 Occurrence records of the species, downloaded from GBIF (https://doi.org/10.15468/dl.7bkqza), were used to determine their distribution across different states and union territories, land-use and landcover (LULC) classes, ecoregions, anthropogenic biomes and climate classes in India. LULC information for each of the occurrence records was extracted from the classified image of the country (Reddy et al., 2015). Species' occurrences were further determined across 51 ecoregions (Olson et al., 2001) and 18 anthropogenic biomes (Ellis and Ramankutty, 2008) present in India. The habitat information at coarser and finer sub-system levels was collected from literature and global databases. The realized climatic niche of each species was characterized for annual mean temperature and precipitation, and their occupancy of the Köppen-Geiger climate classes was ascertained using the $\mathrm{kgc}$ package (Bryant et al., 2017) in R.

\subsection{Assessment of data quality}

The data quality was assessed based on reliability, usability, and accessibility. The individual data records of the dataset were extracted from peer-reviewed articles and databases that maintain detailed profiles of a large number of species, are frequently updated, and provide traceable data sources. Therefore, the curated data should be considered reliable and consistent. We further adopted a multistep pipeline for technical validation of the curated data. This included random and iterative data checking by individual team members to minimize curator's bias, avoid omission error and increase the data accuracy before inclusion in the database. To ensure smooth usability of the database, we arranged individual variables in separate .csv files with consistent species names across the data files. The data files were made accessible without any restriction of use through an online data repository and a dedicated website (see 'Data availability'). A RShiny application (Chang et al., 2020) was created (and embedded on the website) for easy retrieval of species- or variable-specific data through 
query-based search of the database (see details in Supporting information; Fig.2 shows an example search result).

\section{Usage notes}

140 The primary objective behind curating ILORA is to provide a comprehensive, easy-to-access, policy, and research-relevant database for alien vascular plant species of India. It contains occurrence data and the alien status of a species, both of which were considered as essential variables for invasion monitoring (Latombe et al., 2017). These records can be incredibly useful for stakeholders working on alien plant species in India. It also allows users to comprehend the socio-economic drivers of alien plant spread in the country and formulate appropriate trading policies and quarantine measures for the prevention of future expansion.

Alien species databases are not complete and stable units; dynamism lies at the core of the data records and thus, they are open to suggestions and future updates. ILORA also has provisions for the incorporation of data submitted by the users like researchers, stakeholders and the general public. The submitted data will undergo thorough quality checks by the curators (and domain experts as and when required) before integration into the database. All user-submitted data will accompany source information to ensure full credit to the content providers. This bidirectional information exchange is envisaged to increase the data resolution and would broaden the scope of the database.

\section{General patterns}

Curating data from 22 sources, ILORA version 1.0 incorporates attributes of 1747 alien vascular plant species of India in thirteen data variables. Of these, two variables, namely the species categorization and general information, contain data for all the species (Fig.3A). The database contains the recorded common names of 1575 species and vernacular names of 583 species in 23 languages. For the remaining 11 data variables, 1671 species have information for one or more variables whereas data are missing for 76 species (Fig.3B). Among the three categories of alien flora (invasive, naturalized, and casual, Fig.3C), average data availability is maximum for invasive aliens followed by naturalized and casual aliens (Fig.3D). At the taxonomic level, the alien species (invasive, naturalized, and 

Poaceae as the most represented families. Out of the 764 genera, 530 genera have species belonging to either one of the three categories (invasive $=76$, naturalized $=72$, casual $=481$ ) whereas 21 genera have species of all three categories. naturalized ranges at TDWG Level 4 for 1344 species. Introduction pathway information was available for 1038 species. Available information indicated that the Americas contributed most of the alien species and introduction for ornamental purposes was found to be the dominant introduction pathway (Fig.4).

Herbaceous growth form was predominant across all five categories of species (Fig.5A). The data on potential habitats of 459 species identifies 38 subcategories that are combined into five coarser levels. The database is also populated with 40,724 occurrence records for 889 species, recorded across 34 Land-Use and Land-Cover (LULC) classes, 18 anthromes, 42 ecoregions and 15 climate classes in India. The invasive aliens were found to occupy the maximum number of LULC classes, anthromes and ecoregions (Fig.5B). Among the 36 states and union territories, Tamil Nadu has the highest number of alien flora. Further, 50 subcategories of uses have also been recorded for 1159 species, which were combined into thirteen Level 1 uses (Fig.5C). The majority of species have environmental uses (Fig.5D). The online nursery data for 442 species revealed a higher average market price of native and cryptogenic aliens compared to that of the invasive, naturalized, and casual aliens (Fig.5E).

\section{Related works}

The introduction pathway and usage data have previously been utilised to propose a set of policy interventions to prevent and control plant invasions in India (Banerjee et al., 2021a). Considering a subset of species, another study identified the variables' influence on naturalization and invasion success of alien plants in India (Banerjee et al., 2021b).

\section{Conflict of interest}




\section{Author contributions}

$190 \mathrm{AKB}$ and AM conceptualized the idea; VP and AKB developed the methodology; VP, CP and AKB 191 curated the data; all authors validated the data; CP, KP and ARB analysed the data; AKB supervised

192 the project; VP wrote the original draft, which was reviewed by all authors.

\section{Data availability}

194 The data records, along with the detailed information files and R scripts, are archived in the online 195 repository Figshare (DOI: 10.6084/m9.figshare.13677460). ILORA website

196 (https://ilora2020.wixsite.com/ilora2020) can also be used to retrieve data records through query-

197 based search.

\section{Acknowledgements}

199 We express our sincere gratitude to our respective institutions and universities for giving us the

200 logistic support, which was an essential requirement in the absence of any specific grant for

201 conducting this research. We are thankful to the associate editor and two reviewers (Prof. Marcel

202 Rejmánek and one anonymous reviewer) for their valuable comments, which have greatly improved

203 the manuscript and database quality. We would also like to thank Prof. Mark van Kleunen, Prof. John

204 Ross Wilson and Dr. Bharat Babu Shrestha, for their thoughtful comments on an earlier version of the 205 manuscript and database. 


\section{References}

Banerjee, A.K., Khuroo, A.A., Dehnen-Schmutz, K., Pant, V., Patwardhan, C., Bhowmick, A.R., Mukherjee, A., 2021a. An integrated policy framework and plan of action to prevent and control plant invasions in India. Environmental Science \& Policy 124, 64-72.

Banerjee, A.K., Prajapati, J., Bhowmick, A.R., Huang, Y., Mukherjee, A., 2021b. Different factors influence naturalization and invasion processes - A case study of Indian alien flora provides management insights. J. Environ. Manage. 294, 113054.

Brummitt, R.K., Pando, F., Hollis, S., Brummitt, N., 2001. World geographical scheme for recording plant distributions. Hunt Institute for Botanical Documentation, Carnegie Mellon University, Pittsburgh, PA.

Bryant, C., Wheeler, N.R., \&, R.F., French, R.H., 2017. kgc: Koeppen-Geiger Climatic Zones R package version 1.0.0.2.

Chang, W., Cheng, J., Allaire, J., Xie, Y., McPherson, J., 2020. shiny: Web Application Framework for R. R package version 1.4.0.2. https://cran.r-project.org/package=shiny.

Cook, F.E., 1995. Economic botany data collection standard - Prepared for the International Working Group on Taxonomic Databases for Plant Sciences (TDWG). Royal Botanic Gardens (Kew), Richmond, UK.

Ellis, E.C., Ramankutty, N., 2008. Putting people in the map: anthropogenic biomes of the world. Front. Ecol. Environ. 6, 439-447.

Essl, F., Bacher, S., Genovesi, P., Hulme, P.E., Jeschke, J.M., Katsanevakis, S., Kowarik, I., Kühn, I., Pyšek, P., Rabitsch, W., Schindler, S., van Kleunen, M., Vilà, M., Wilson, J.R.U., Richardson, D.M., 2018. Which taxa are alien? Criteria, applications, and uncertainties. Bioscience 68, 496-509.

Harrower, C., Scalera, R., Pagad, S., Schonrogge, K., Roy, H., 2018. Guidance for interpretation of CBD categories on introduction pathways. Technical note prepared by IUCN for the European Commission, p. 100.

Inderjit, Pergl, J., van Kleunen, M., Hejda, M., Babu, C.R., Majumdar, S., Singh, P., Singh, S.P., Salamma, S., Rao, B.R.P., Pyšek, P., 2018. Naturalized alien flora of the Indian states: biogeographic patterns, taxonomic structure and drivers of species richness. Biol. Invasions 20, 1625-1638.

Khuroo, A.A., Reshi, Z.A., Malik, A.H., Weber, E., Rashid, I., Dar, G., 2012. Alien flora of India: taxonomic composition, invasion status and biogeographic affiliations. Biol. Invasions 14, 99-113.

Kindt, R., 2020. WorldFlora: An R package for exact and fuzzy matching of plant names against the World Flora Online taxonomic backbone data. Applications in Plant Sciences 8, e11388.

Latombe, G., Pyšek, P., Jeschke, J.M., Blackburn, T.M., Bacher, S., Capinha, C., Costello, M.J., Fernández, M., Gregory, R.D., Hobern, D., Hui, C., Jetz, W., Kumschick, S., McGrannachan, C., Pergl, J., Roy, H.E., Scalera, R., Squires, Z.E., Wilson, J.R.U., Winter, M., Genovesi, P., McGeoch, M.A., 2017. A vision for global monitoring of biological invasions. Biol. Conserv. 213, 295-308.

Lenzen, M., Moran, D., Kanemoto, K., Foran, B., Lobefaro, L., Geschke, A., 2012. International trade drives biodiversity threats in developing nations. Nature 486, 109-112.

Olson, D.M., Dinerstein, E., Wikramanayake, E.D., Burgess, N.D., Powell, G.V., Underwood, E.C., D'amico, J.A., Itoua, I., Strand, H.E., Morrison, J.C., 2001. Terrestrial Ecoregions of the World: A 
bioRxiv preprint doi: https://doi.org/10.1101/2021.05.28.446252; this version posted September 13, 2021. The copyright holder for this preprint (which was not certified by peer review) is the author/funder. All rights reserved. No reuse allowed without permission.

New Map of Life on Earth A new global map of terrestrial ecoregions provides an innovative tool for conserving biodiversity. Bioscience 51, 933-938.

Pagad, S., Genovesi, P., Carnevali, L., Schigel, D., McGeoch, M.A., 2018. Introducing the Global

Pyšek, P., Richardson, D.M., Rejmánek, M., Webster, G.L., Williamson, M., Kirschner, J., 2004. ecologists. Taxon 53, 131-143.

R Core Team, 2020. R: A Language and Environment for Statistical Computing. R Foundation for Statistical Computing, Vienna, Austria.

Reddy, C.S., Jha, C.S., Diwakar, P.G., Dadhwal, V.K., 2015. Nationwide classification of forest types of India using remote sensing and GIS. Environ. Monit. Assess. 187, 777.

Sankaran, K.V., Khuroo, A., Raghavan, R., Molur, S., Kumar, B., Wong, L.J., Pagad, S., 2020. Global 13; https://doi.org/10.15468/uvnf8m.

van Kleunen, M., Dawson, W., Essl, F., Pergl, J., Winter, M., Weber, E., Kreft, H., Weigelt, P., 100-103.

van Kleunen, M., Pyšek, P., Dawson, W., Essl, F., Kreft, H., Pergl, J., Weigelt, P., Stein, A., F.J., Cárdenas, D., Cárdenas-Toro, J., Castaño, N., Chacón, E., Chatelain, C., Conn, B., de Sá Dechoum, M., Dufour-Dror, J.-M., Ebel, A.L., Figueiredo, E., Fragman-Sapir, O., Fuentes, N., Groom, Q.J., Henderson, L., Inderjit, Jogan, N., Krestov, P., Kupriyanov, A., Masciadri, S., Meerman, J., Morozova, O., Nickrent, D., Nowak, A., Patzelt, A., Pelser, P.B., Shu, W.-s., Thomas, J., Uludag, A., Velayos, M., Verkhosina, A., Villaseñor, J.L., Weber, E., Wieringa, J.J., Yazlık, A., Zeddam, A., Zykova, E., Winter, M., 2019. The Global Naturalized Alien Flora (GloNAF) database. Ecology 100, 
Table 1. Overview of the data records of ILORA version 1.0 representing the contents and data type for each of the twenty data files

\begin{tabular}{|c|c|c|}
\hline & File name (with extension) & Data contents \\
\hline 1 & ILORA_1_SpCategorization.csv & $\begin{array}{l}\text { The reported origin and invasion status of the } \\
\text { alien species present in India }\end{array}$ \\
\hline 2 & ILORA_1a_Sp.Categorization.Metadata.csv & $\begin{array}{l}\text { Metadata for determining origin and invasion } \\
\text { status }\end{array}$ \\
\hline 3 & ILORA_2_GeneralInformation.csv & $\begin{array}{l}\text { Common and vernacular names, life form, } \\
\text { duration, and type }\end{array}$ \\
\hline 4 & ILORA_3_NativeRange.csv & Native range at TDWG* Level 2 \\
\hline 5 & ILORA_4_Introduction.csv & $\begin{array}{l}\text { Month and year of first reported occurrence in } \\
\text { India; introduction pathway(s) }\end{array}$ \\
\hline 6 & ILORA_5_EconomicUses.csv & Economic uses at TDWG* Level 1 \\
\hline 7 & ILORA_6_MarketDynamics.csv & $\begin{array}{l}\text { Price and number of plants/seeds sold in two } \\
\text { online nurseries of India }\end{array}$ \\
\hline 8 & ILORA_7_Habitat.csv & Potential habitat(s) \\
\hline 9 & ILORA_8_NaturalizedRange.csv & $\begin{array}{l}\text { Naturalized ranges at global and Indian scale at } \\
\text { TDWG* Level } 4\end{array}$ \\
\hline 10 & ILORA_9_Occurrence.csv & Latitude and longitude data \\
\hline 11 & ILORA_10_Distribution.csv & $\begin{array}{l}\text { Distribution in Indian states and union } \\
\text { territories }\end{array}$ \\
\hline 12 & ILORA_11_LULC.csv & Land-Use and Land-Cover categories inhabited \\
\hline 13 & ILORA_12_Anthromes.csv & Indian anthromes inhabited \\
\hline 14 & ILORA_13_Ecoregions.csv & Indian ecoregions inhabited \\
\hline 15 & ILORA_14_Climate.csv & $\begin{array}{l}\text { Köppen-Geiger climate classes of India } \\
\text { inhabited; the temperature and precipitation } \\
\text { data }\end{array}$ \\
\hline 16 & ILORA_15_Summary.csv & $\begin{array}{l}\text { Status (presence/absence) of data for each of } \\
\text { the above mentioned } 14 \text { data files for each of } \\
\text { the alien plant species }\end{array}$ \\
\hline 17 & ILORA_16_Cultivated.Species.csv & Standardized species names of cultivated aliens \\
\hline 18 & ILORA_17_R.Codes.txt & $\mathrm{R}$ codes used to extract variable information \\
\hline 19 & ILORA_Methods.pdf & $\begin{array}{l}\text { Document having information on rationale of } \\
\text { variable selection, data sources, search queries; } \\
\text { future scopes of data enrichment }\end{array}$ \\
\hline 20 & ILORA_HowToRead.pdf & $\begin{array}{l}\text { Document having information of the data types } \\
\text { recorded in columns in each of the data file }\end{array}$ \\
\hline
\end{tabular}




\section{Figures}

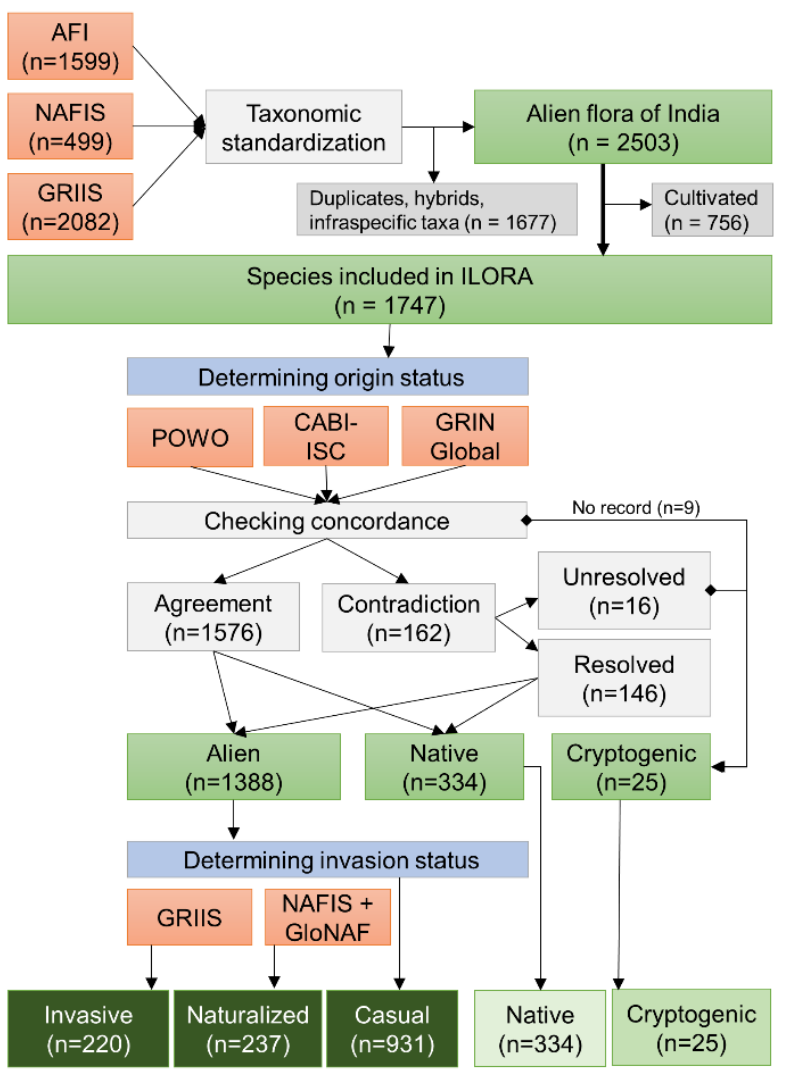

281 Fig.1: The methodology followed for the categorization of the Indian alien flora [AFI - Alien Flora of

282 India (Khuroo et al., 2012); NAFIS: Naturalized Alien Flora of the Indian States (Inderjit et al., 2018);

283 GLONAF: The Global Naturalized Alien Flora database (van Kleunen et al., 2019); GRIIS: Global

284 Register of Invasive and Introduced Species (Sankaran et al., 2020)] 


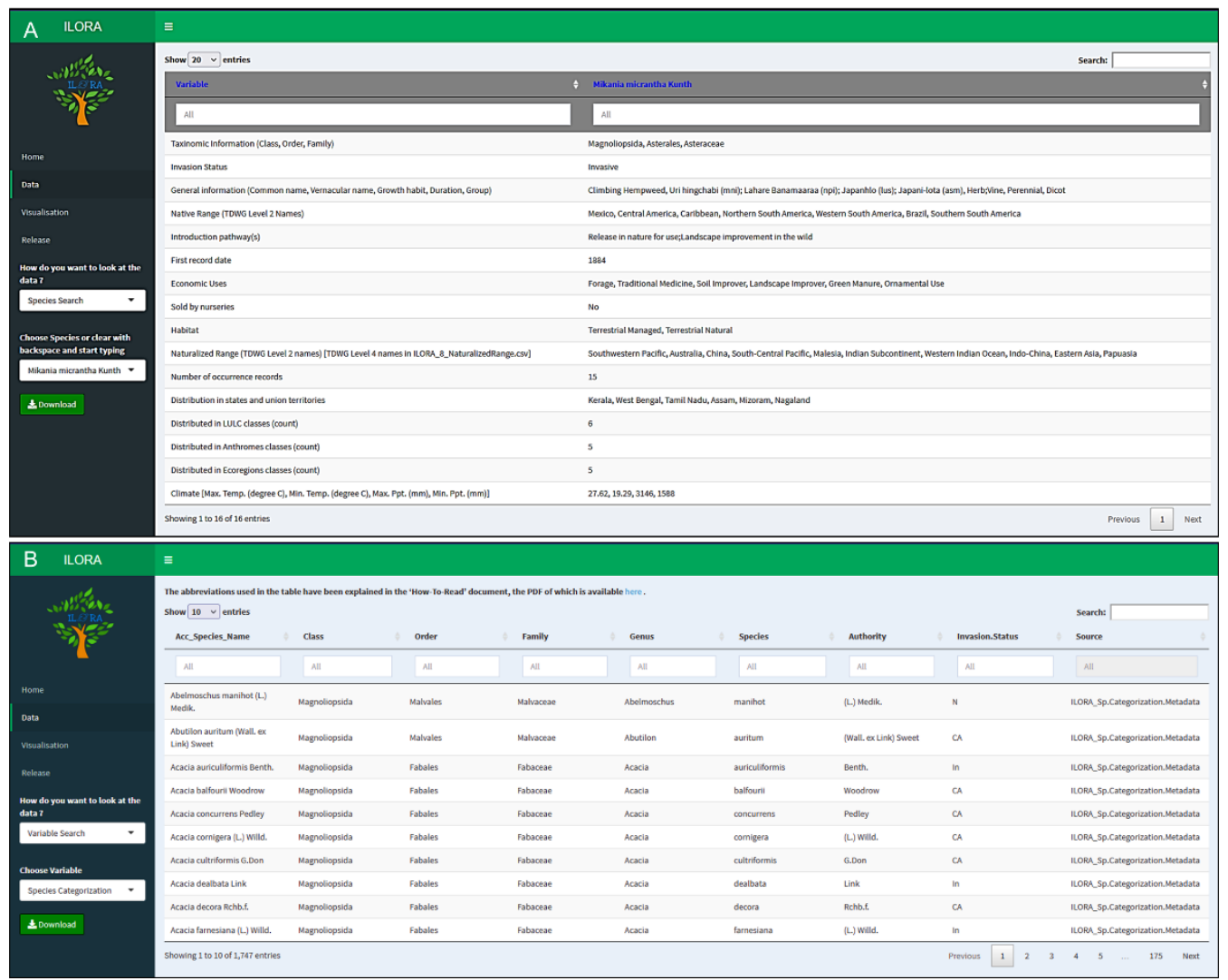

Fig. 2: A snapshot of the database search result for - (A) an individual species (Mikania micrantha

287 Kunth, as an example) and (B) a variable (Species categorization). The variables for species-specific search (A) follow the arrangement of the data records in the database; note the taxonomic information are displayed separately from the invasion status, as the introduction pathway(s) and the first record date, thus making the number of variables equal to 16 

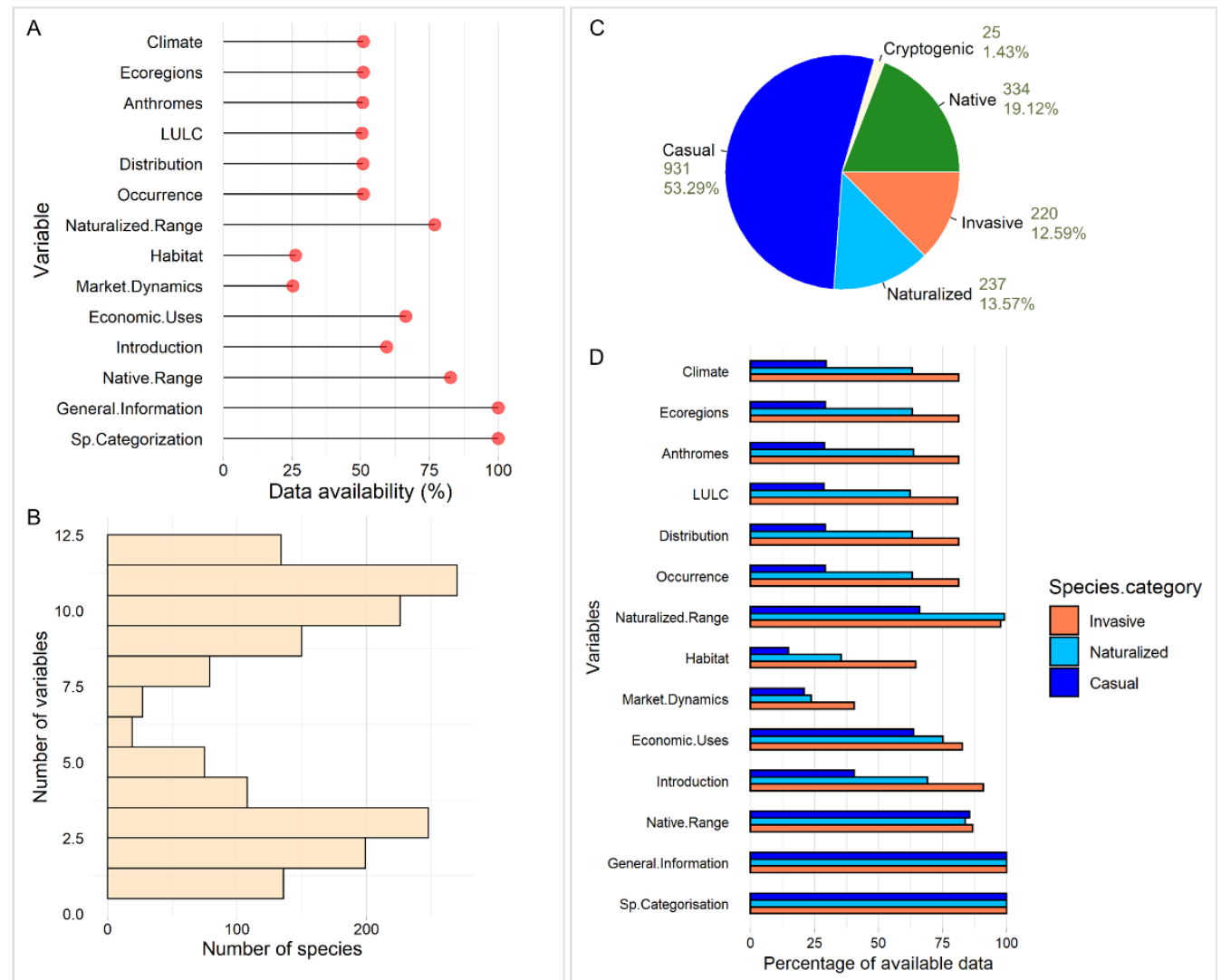

292 Fig 3. Data availability in the ILORA database - (A) percentage of available data for each of the 14

293 variables; (B) the frequency histogram showing numbers of species ( $\mathrm{n}=1671$ having data for at least

294 one variable) for each of the 12 variables (i.e., excluding two variables, species categorization and

295 general information having no missing data); (C) the pie chart showing the numbers and percentages

296 of the alien flora across five categories; (D) the bar plot showing the percentage of available data for

297 each of the 14 variables for three categories of alien species (invasive, naturalized and casual) 


\section{IP: Introduction Pathways -}

1.2: Erosion control; 1.5: Landscape improvement; 1.6: Conservation; 1.7: Release in nature for use; 2.1: Agriculture; 2.9: Ornamental; 2.others: Botanical garden + Aquarium species + Forestry + Horticulture + Food + Other escape; 3.4.5: Contaminant (Nursery, Food, Plant,

Seed, Habitat materials), Stowaway (Packing, Ballast water), Interconnected waterways

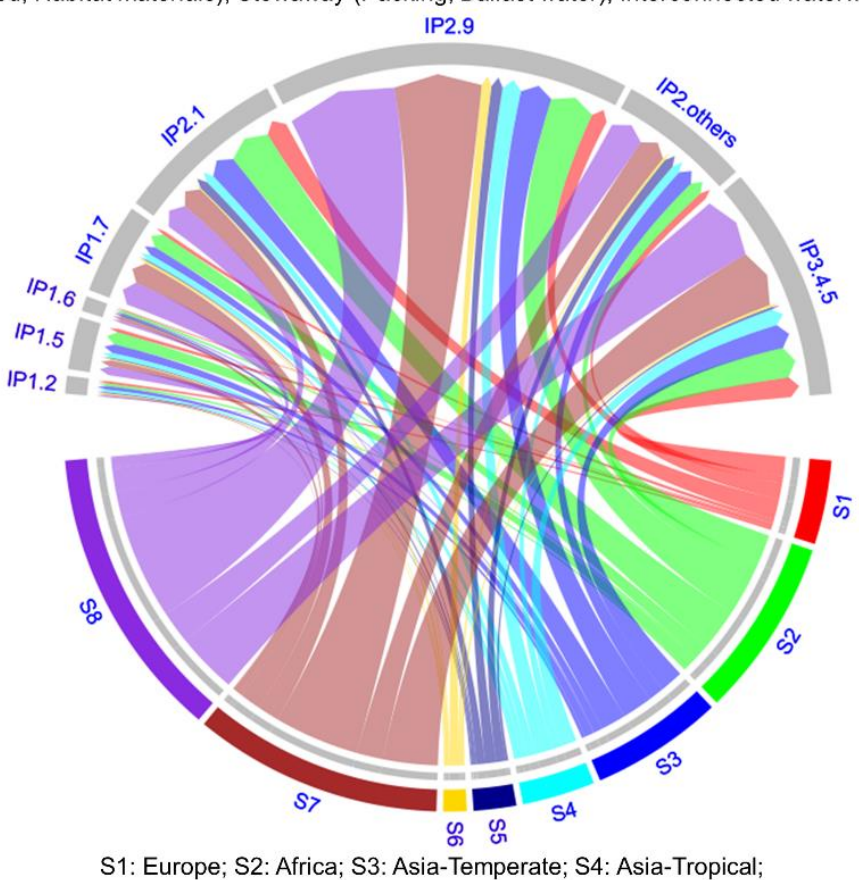

S5: Australasia; S6: Pacific; S7: Northern America; S8: Southern America

Fig.4. Flows of alien species between native range and introduction pathways. The chord diagram

shows the number of alien species $(n=317$, considering invasive, naturalized and casual alien species 
A

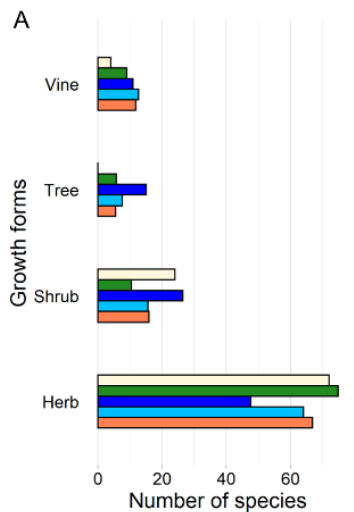

B

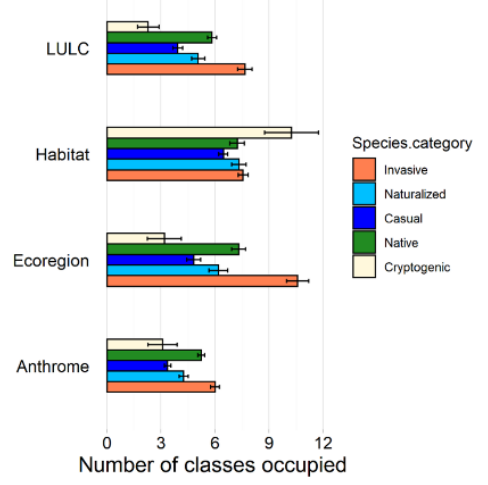

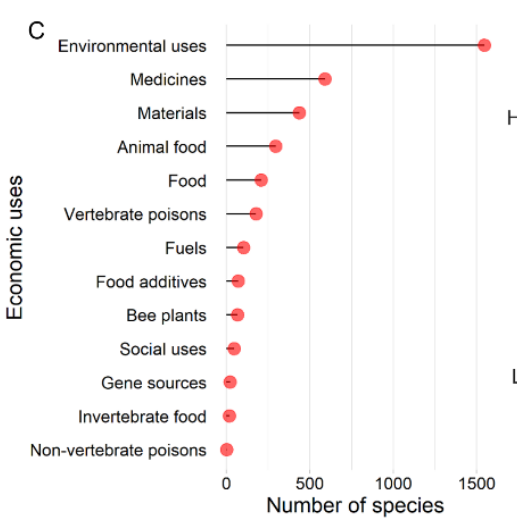

$E$
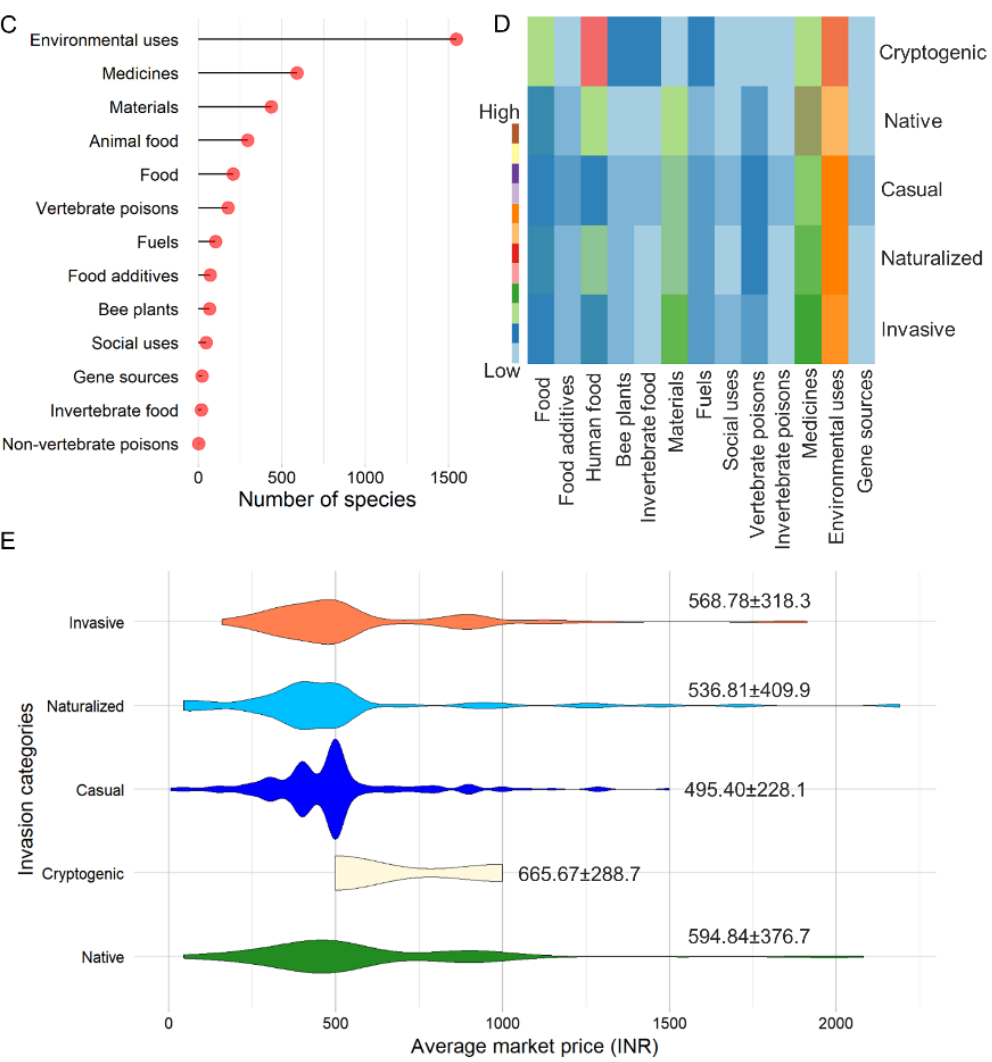

Fig.5. Visualization of variables across five categories of species included in the database - (A) growth form, (B) average $( \pm$ SE) number of occupied anthromes, ecoregions, habitats and LULC classes, (C) number of economic uses for five categories together, (D) heatmap showing number of economic uses for each of the five categories of species, (E) violin plot showing the distribution of market price values (with mean \pm SE values showing above each plot) 